\title{
WHAT ONE FEELS AND WHAT ONE KNOWS: THE INFLUENCE OF EMOTIONS ON ATTITUDES AND INTENTIONS TOWARDS KNOWLEDGE SHARING ${ }^{1}$
}

\author{
Bart van den Hooff \\ bhooff@ feweb.vu.nl \\ VU University Amsterdam, Faculty of Economics and Business Administration \\ Alexander Schouten \\ aschouten@feweb.vu.nl \\ VU University Amsterdam, Faculty of Economics and Business Administration \\ Stojan Simonovski \\ s.simonovski@student.tue.nl \\ Eindhoven University of Technology
}

\begin{abstract}
This paper provides theoretical and empirical insight in the relationship between emotions and knowledge sharing. Pride (an ego-focused emotion) and empathy (an other-focused emotion) are related to eagerness and willingness to share knowledge. Our hypotheses were tested by means of a survey in which respondents were asked to evaluate one of four different scenarios. Pride and empathy were found to affect eagerness and willingness to share knowledge. Furthermore, these emotions also influenced knowledge sharing intentions, partly mediated by eagerness and willingness. Both eagerness and willingness mediate the relationship between pride and knowledge sharing intention, whereas only willingness turned out to mediate the relationship between empathy and knowledge sharing. These findings have a number of implications for theory on both knowledge sharing and emotions.
\end{abstract}

Key words: Knowledge sharing; Emotions; Attitudes; Intentions

${ }^{1}$ Corresponding author: Bart van den Hooff, VU University Amsterdam, De Boelelaan 1105, 1081 HV Amsterdam, The Netherlands, ++31 20598 6062, b.j.vanden.hooff@vu.nl. 


\section{INTRODUCTION}

As knowledge is often seen as one of individuals' prime assets in today's knowledge economy, it can be assumed that people will have strong feelings about sharing their knowledge. Common sense would dictate, for instance, that people will be more inclined to share their knowledge with people towards whom they feel positive emotions (liking, empathy) than would be the case with people towards whom they have negative emotions (anger, disappointment). Therefore, the connection between emotions and knowledge sharing is a very interesting one to research, but one that has not been the subject of much empirical research to date. This paper contributes to the literature by filling that void by integrating theoretical insights on emotions and knowledge sharing, and providing a thorough empirical exploration of the relationship between these two concepts.

Building on a conceptualization of knowledge sharing as "making individual knowledge collective", a distinction is made between ego-focused (or individual) emotions on the one hand, and other-focused (or collective) emotions on the other (Aaker \& Williams, 1998; Markus \& Kitayama, 1991). A prime example of an ego-focused emotion is pride, whereas empathy is seen as a typical other-focused emotion (Aaker \& Williams, 1998; Mueller, 1987). In this study, pride and empathy are related to two previously distinguished attitudes towards knowledge sharing: eagerness, a strong internal drive to share what one knows, and willingness, which is also a positive attitude towards knowledge sharing, but one that is more conditional (De Vries, Van den Hooff \& De Ridder, 2006). Where eagerness is primarily derived from an individual passion for a practice, willingness stems from a focus on the collective's interests (De Vries et al., 2006). These attitudes, in turn, are assumed to be positively related to an individual's intention to share knowledge.

Based on these foundations, the research question that is central to this study is:

"How do emotions (pride and empathy) influence attitudes towards knowledge sharing (eagerness and willingness) and knowledge sharing intentions?

In the following paragraphs, we first present our theoretical foundations with regard to attitudes and intentions towards knowledge sharing, and emotions. Based on these foundations, we present five hypotheses which were tested through a scenario experiment in a large IT organization. After elaborating on the setup of the empirical study, we discuss the results of the experiment and relate these to our hypotheses. In the discussion section, the theoretical implications of our findings are discussed, as well as avenues for future research.

\section{EMOTIONS AND KNOWLEDGE SHARING}

In order to discuss the possible influence of emotions on knowledge sharing attitudes and behavior, we first define knowledge sharing and distinguish two different attitudes towards sharing: eagerness and willingness. Next, we discuss how ego-focused and other-focused emotions (in this case, pride and empathy) are assumed to be related to these attitudes. 


\subsection{Knowledge sharing attitudes and intentions}

Knowledge sharing is the process where individuals mutually exchange their (tacit and explicit) knowledge and jointly create new knowledge (De Vries, Van den Hooff \& De Ridder, 2006). This implies that individuals make their knowledge collective through sharing, which means that the relationship between individual and collective (community, group, team or organization) is a central aspect of knowledge sharing behavior. For the collective to be able to benefit from its potential "intellectual capital", individual members of the collective must make this knowledge available: share their knowledge with co-workers (Van den Hooff \& Huysman, 2009).

In the literature on knowledge management, the last decade has seen the emergence of a "practice-based perspective" (Hislop, 2002) which emphasizes that knowledge is personal, subjective, socially determined, primarily tacit, and related to daily practice (Cook \& Brown, 1999; Brown \& Duguid, 2001). As a consequence, the sharing of knowledge cannot be forced, but results from a shared intrinsic motivation to share, a motivation which is largely determined by the relationship between individual and collective interests (Wasko \& Faraj, 2005), but also by the interest that individuals have in their practice, in the subject matter of their work (Wenger, McDermott \& Snyder, 2002). Therefore, the attitudes that individuals have towards the collective, as well as to the subject of that collective's practices, is likely to be an important determinant of their knowledge sharing behavior. An attitude involves "categorization of an object along an evaluative dimension" (Fazio, Chen, McDonel \& Sherman, 1981: 341), in other words, the extent to which an individual evaluates the object (in this case, the collective and the practice) in positive or negative terms.

With regard to these attitudes, we build on the work of De Vries et al. (2006), who discuss and empirically test the distinction between two attitudes towards knowledge sharing: eagerness and willingness. Willingness is defined as the extent to which an individual is prepared to grant other group members access to his or her individual intellectual capital. Eagerness, on the other hand, is defined as the extent to which an individual has a strong internal drive to communicate his or her individual intellectual capital to other group members. Although they are both positive attitudes towards knowledge sharing (as opposed to, for instance, an outright unwillingness to share knowledge) and they are found to be positively related to knowledge sharing, there are some important differences, which are related to the distinction made above between attitudes towards the collective and attituds towards the practice.

Willingness is focused on the collective, it is a positive attitude towards the community, the team, the organization. Based on positive feelings towards the collective and its interestes, willingness stands for a readiness to reply to colleagues kindly. In a way, willingness to share implies a conditional way of knowledge sharing. Actors are willing to provide access to their personal knowledge, but because their focus is on the collective interest, they expect others to behave similarly-and focus on the collective interest as well. They will not easily take the initiative to actively share their knowledge if they are uncertain about whether others are also willing to contribute to the group's interest by sharing knowledge. For people who are willing to 
share their knowledge, the norm of reciprocity is important - they expect others to contribute as well (Adler\&Kwon, 2002; Nahapiet \& Ghoshal, 1998).

Eagerness, on the other hand, is focused on the practice around which the collective creates and shares knowledge. Eagerness is a positive attitude towards the subject matter of that practice, towards the content being created and exchanged, and specifically to one's own expertise with regard to that practice. An actor who is eager to share knowledge will spout his or her knowledge, without paying too much attention towards what other members of the collective do. Their passion for the practice creates a strongly felt need to "spread the word", share their passion and expertise. For eager individuals, others' behavior is much less important: whether other group members will also share their knowledge is not really relevant to them-it is the subject about which knowledge is being shared that triggers them. People are eager to let others know what they know because they themselves consider it valuable and feel a strong drive to showcase their expertise.

Although both attitudes have different foundations (a focus on the collective and a focus on the practice), they have in common that they are positive attitudes towards knowledge sharing, and consequently, both are likely to be positively related to knowledge sharing. De Vries et al. (2006) confirm this, finding a positive influence of both eagerness and willingness on knowledge sharing. Although their findings establish an influence of attitudes on behavior, most research on the relationships between attitudes and behavior finds that this relationship is mediated by intentions (Bagozzi, 1981; Davis, Bagozzi \& Warshaw, 1989; Fishbein \& Ajzen, 1975; Warshaw, 1980). Kim and Hunter (1993) present a meta-analysis of research on the attitudebehavior relationship and show convincingly that intention is indeed a mediator between these two concepts, and that intentions are good predictors of actual behavior. Furthermore, actual knowledge sharing behavior is very difficult to measure, unless one resorts to contributions to online forums and the like. Even in a laboratory setting, knowledge sharing behavior is very difficult to operationalize (although Kane, Argote and Levine (2005) show an interesting way to do this). For these reasons, our study focuses on knowledge sharing intentions as a dependent variable.

\subsection{Emotions and attitudes}

Emotion is an elusive concept, and a wide variety of definitions have been used to make sense of this concept. Kleinginna and Kleinginna (1981) for instance, present an impressive list of definitions of emotions and suggest the following "consensual" definition (1981, p. 355):

"Emotion is a complex set of interactions among subjective and objective factors, mediated by neural-hormonal systems, which can (a) give rise to affective experiences such as feelings of arousal, pleasure/displeasure; (b) generate cognitive processes such as emotionally relevant perceptual effects, appraisals, labeling processes; (c) activate widespread physiological adjustments to the arousing conditions; and (d) lead to behavior that is often, but not always, expressive, goaldirected, and adaptive. 
A second integrative and usable definition of emotions is provided by Bagozzi, Gopinath and Nyer (1999, p. 184):

"By emotions, we mean a mental state of readiness that arises from cognitive appraisal of events of thought; has a phenomenological tone; is accompanied by physiological process; is often expressed physically (eg. in gestures, posture; facial features) and may result in specific actions to affirm or cope with emotion, depending on its nature and meaning for the person having it."

What becomes clear from these definitions is that an emotion (a) is a mental state, (b) has an affective as well as a cognitive nature, (c) is expressed in a physical way and (d) leads to actions and behaviors that are an expression of, or way to cope with, this mental state. It is important to distinguish emotions from attitudes, because attitudes (evaluative judgments of an object, as defined above) are mental states as well. According to Bagozzi et al. (1999), emotions are more intense than attitudes in terms of both feeling and expression, and they arise from a different source. Emotions arise because of changes in person-related situations or events, based on some state of arousal which is by definition transient. Attitudes, on the other hand, are less personal, can also be aimed at mundane objects, and are more stable. Attitudes can be stored and retrieved, whereas emotions are situational and thus volatile. Since both emotions and attitudes are evaluative and affective in nature, however, they are likely to be related.

Numerous classifications of emotions exist, but for our study an important distinction is the one between ego-focused and other-focused emotions, since the relationship between individual and collective interests is crucial in explaining knowledge sharing. Aaker and Williams (1998) use this distinction in their study on the role of emotions in persuasive appeals. The distinction between ego-focused and other-focused is established on the basis of "the degree to which specific emotions systematically vary in the extent to which they follow from and also foster or reinforce, an independent versus interdependent self" (Markus and Kitayama, 1991, p. 235). Ego-focused emotions are associated with an individual's internal state, "to the exclusion of others, and (...) consistent with the need for individual awareness, experience and expression." (Aaker and Williams, 1998, p 242). Examples of ego-focused emotions can be pride, happiness, anger etc. Other-focused emotions, on the other hand, are associated with others with whom the individual identifies, and are "consistent with the need for unity, harmony and the alignment of one's actions with those others" (Aaker and Williams, 1998, p. 242). Examples of other-focused emotions are empathy, peacefulness, indebtedness etc. In this study, we will focus on one specific ego-focused emotion: pride; and one specific other-focused emotion: empathy. This focus is justified by the fact that these are prime examples of ego-focused and other-focused emotinos, they are common and universal emotions across different cultural settings (Matsumoto, 1989), have been previously researched in different contexts (Aaker et al., 1986; Mueller 1987), and are likely to be associated to both eagerness and willingness to share.

Empathy refers to the reactions of one individual to the observed experiences of another (Davis, 1983) and implies collective concern and pro-social behavior (Aaker \& Williams, 1998; Eisenberg \& Fabes, 1990; Roberts \& Strayer, 1996). As such, empathy is strongly focused on the collective. Hence, it is likely that empathy will positively influence the willingness to share knowledge, as this attitude is also characterized by a focus on the collective. However, empathy 
can also enhance the feeling that what one knows is very valuable to others, enhancing one's own passion for the practice and thus positively influencing the eagerness to share.

Pride manifests itself when an individual evaluates his or her own performance in a positive light (Bagozzi et al., 1999), leading to a higher self-esteem (Zammuner, 1996). As such, is a very individually oriented emotion, which is likely to be associated with expertise, self-efficacy and self-rated performance (Williams \& DeSteno, 2008). When an individual is proud of his or her expertise and experience in his or her practice, this individual is more likely to be eager to share knowledge about this practice. Thus, pride is likely to positively influence an individual's eagerness to share their knowledge. On the other hand, pride is especially evoked when one's performance is recognized, when members of the collective acknowledge the individual's skills, expertise and contributions. So in spite of the fact that pride is a "self-consious" emotion, it is likely to be enhanced by public appraisal (Williams \& DeSteno, 2008). Consequently, pride can also lead to a stronger conviction that one has valuable things to contribute to the group's performance, thus also positively influencing the willingness to share.

Although both emotions are assumed to be positively related to both attitudes, empathy is assumed to be primarily associated with willingness (both being primarily other-focused), and pride with eagerness (both ego-focused). Consequently, we expect that willingness will primarily mediate the relationship between empathy and knowledge sharing intentions, while eagerness will primarily mediate the relationship between pride and knowledge sharing intentions.

We empirically tested the relationship between emotions, attitude and intention in an experiment in which respondents were asked to evaluate one of four different scenarios (designed to invoke, respectively, a high level of pride, a low level of pride, a high level of empathy and a low level of empathy), and indicate what their attitude towards sharing their knowledge would be in the situation sketched in the scenario (measuring eagerness and willingness) as well as how likely they would be to share their knowledge in that situation (measuring intention to share). With regard to these conditions, the theoretical framework discussed above leads to the following hypotheses:

H1. Both eagerness and willingness to share knowledge will be higher in the high pride than the low pride condition.

H2. Both eagerness and willingness to share knowledge will be higher in the high empathy than the low empathy condition.

H3a. Eagerness and willingness will mediate the relationship between pride and empathy on the one hand, and intention to share knowledge on the other hand.

H3b. The indirect effect of pride on intention to share knowledge via eagerness will be stronger than the effect via willingness.

H3c. The indirect effect of empathy on intention to share knowledge via willingness will be stronger than the effect via willingness.

In the following section, we will discuss in more detail the methods used to test these hypotheses. 


\section{METHOD}

The empirical study in which our hypotheses were tested, was part of a larger company survey on barriers to knowledge sharing within the organization. This survey was sent out to 450 employees from two departments of the Dutch branch of a large international IT company. Of these 450 employees, 252 filled out the survey (56\%). Unfortunately, for privacy reasons, we could not ask respondents' age or gender. All employees were trained experts in their field of either software development or general technology services. All respondents were involved in high-tech, knowledge intensive work (software engineering, hardware development, technological consultancy, et cetera). Therefore, sharing knowledge was of high importance to their daily practice.

To test our hypotheses, we designed four different scenarios which were manipulated to stimulate either pride or empathy. In each scenario, respondents were presented a hypothetical situation in which one of their colleagues asked them for help on a certain topic on which the respondent was knowledgeable, but which was not related to their current projects. Respondents were told that the person requesting their help was working on a tight deadline and really needed help, but respondents were also told they were in no way obliged to help the other person.

Respondents were randomly assigned to one of the four conditions. In the low pride condition, respondents were told that the person requested help from the respondents because other, more knowledgeable and experienced, persons were unavailable at the moment. In the high pride condition, respondents were told that the person requested the respondent for help because they felt the respondent was the most knowledgeable and experienced person in the field. In the low empathy condition, respondents were told that the person who requested for help was considered unlikeable, irresponsible and generally unwilling to help others. Finally, in the high empathy condition, respondents were told that the person who requested for help was considered likeable, responsible, and generally willing to help others.

\section{1. $\quad$ Measures}

Eagerness and willingness were measured with three items each, based on the scales by De Vries et al. (2006). Knowledge sharing intention was measured with a single item that asked respondents for the likelihood that they would share knowledge in the situation described in the given scenario, on a 5-point scale from (1) highly unlikely to (5) highly likely. Finally, to check if the manipulations of pride and empathy succeeded, we asked respondents how proud or empathic they felt when they considered the situation. For this we used statements that were insipired by the items used by Aaker \& Williams (1998). Except for knowledge sharing, all items were measures on a 5-point scale from (1) strongly disagree to (5) strongly agree. Items, scales, and Cronbach's alpha's are listed in Table 1. 
Table 1. Scales, items and reliabilities.

\begin{tabular}{|c|c|c|}
\hline Scale & Item & Alpha \\
\hline & $\begin{array}{l}\text { If you consider the situation sketched in the above scenario, to } \\
\text { what extent would you agree with the following statements? }\end{array}$ & \\
\hline Eagerness & $\begin{array}{l}\text { I would feel appreciated for my specific expertise } \\
\text { I would tell my colleagues about things that I know about this } \\
\text { problem, even without their asking me for it } \\
\text { Next to the colleague requesting assistance, I would also try to } \\
\text { convince others of the important of my area of expertise }\end{array}$ & .65 \\
\hline Willingness & $\begin{array}{l}\text { I would try to improve my colleague's performance by } \\
\text { sharing knowledge } \\
\text { I would expect my colleagues to share their knowledge with } \\
\text { me as well when I help them } \\
\text { I would think that sharing my knowledge would contribute to } \\
\text { improved collaboration with my colleagues }\end{array}$ & .80 \\
\hline $\begin{array}{l}\text { Knowledge } \\
\text { sharing intention }\end{array}$ & How likely would it be for you to share your knowledge & - \\
\hline Pride & $\begin{array}{l}\text { I would feel good about receiving the deserved recognition for } \\
\text { my work } \\
\text { I would consider myself to be a winner }\end{array}$ & .74 \\
\hline Empathy & $\begin{array}{l}\text { Being with this colleague would be important to me } \\
\text { Creating a positive informal relationship with this colleague } \\
\text { would be important to me }\end{array}$ & .91 \\
\hline
\end{tabular}

\section{RESULTS}

\subsection{Manipulation checks}

We first checked if we were successful in manipulating pride and empathy with our scenarios, by comparing feelings of pride between the low and high pride condition, and by comparing feelings of empathy in the low and high empathy conditions. These comparisons indicated that our manipulations succeeded. Participants in the low pride condition indicated that they would feel less proud $(M=3.37, S D=0.90)$ than respondents in the high pride condition $(M=4.09, S D$ $=0.65), F(1,125)=27.19, p<.001, \eta^{2}=.18$. Similarly, respondents in the low empathy condition indicated that they would less empathic $(M=2.68, S D=0.91)$ than respondents in the high empathy condition $(M=3.70, S D=0.58), F(1,123)=56.06, p<.001, \eta^{2}=.31$.

\subsection{Hypotheses testing}

Hypothesis 1 posed that both eagerness and willingness to share knowledge would be higher in the high pride condition than in the low pride condition. This hypothesis was confirmed for both eagerness, $F(1,125)=20.76, p<.001, \eta^{2}=.30$, and willingness, $F(1,125)=5.46, p<.001, \eta^{2}=$ 
.12. Similarly, hypothesis 2 posed that both eagerness and willingness to share knowledge would be higher in the high empathy condition than in the low empathy condition. This hypothesis was also confirmed for both eagerness, $F(1,123)=47.56, p<.001, \eta^{2}=.28$, and willingness, $F(1$, $123)=32.56, p<.001, \eta^{2}=.21$. Means and standard deviations for all dependent variables across conditions are listed in Table 2.

Table 2. Means and standard deviations across conditions.

\begin{tabular}{|c|c|c|c|c|}
\hline & $\begin{array}{c}\text { Low pride } \\
(\mathrm{n}=65)\end{array}$ & $\begin{array}{c}\text { High Pride } \\
(\mathrm{n}=62)\end{array}$ & $\begin{array}{c}\text { Low empathy } \\
(\mathrm{n}=62)\end{array}$ & $\begin{array}{c}\text { High empathy } \\
(\mathrm{n}=63)\end{array}$ \\
\hline Eagerness & $3.04(0.78)^{\mathrm{a}}$ & $3.84(0.41)^{\mathrm{b}}$ & $3.27(0.72)^{\mathrm{a}}$ & $4.04(0.51)^{\mathrm{b}}$ \\
\hline Willingness & $3.90(0.66)^{\mathrm{a}}$ & $4.32(0.44)^{\mathrm{b}}$ & $3.59(0.80)^{\mathrm{c}}$ & $4.25(0.44)^{\mathrm{b}}$ \\
\hline $\begin{array}{c}\text { Knowledge } \\
\text { sharing intention }\end{array}$ & $3.82(0.86)^{\mathrm{a}}$ & $4.51(0.64)^{\mathrm{b}}$ & $3.46(0.91)^{\mathrm{c}}$ & $4.50(0.67)^{\mathrm{b}}$ \\
\hline $\begin{array}{l}\text { Note. Standard deviations between brackets. Different superscripts within rows indicate } \\
\text { significant differences between conditions, } \mathrm{p}<.05 \text {, Tukey's HSD. }\end{array}$ \\
\hline
\end{tabular}

Hypothesis 3a posed that eagerness and willingness would mediate the relationship between pride and empathy on the one hand, and intention to share knowledge on the other hand. Moreover, we posed that eagerness would more strongly mediate the relationship between pride and knowledge sharing intention ( $\mathrm{H} 3 \mathrm{~b})$, while willingness would more strongly mediate the relationship between empathy and knowledge sharing intention $(\mathrm{H} 3 \mathrm{c})$.

To test our mediation hypotheses, we used the procedure developed by Preacher and Hayes (2008). This procedure has several advantages above other approaches to test mediation, such as the causal steps approach (Baron \& Kenny, 1986). First, multiple mediators can be tested simultaneously, allowing to test the effects of each single mediator controlling for the effect of the other mediators. Second, because a single analysis is used to test the multiple mediator model, the risk of a Type I error is reduced. Third, the method allows for contrasting the different indirect effects in multiple mediator models in order to check whether different indirect effects differ significantly. Finally, the method uses bootstrapping to test the significance of the mediated effects, eliminating the need for multivariate normality which is unlikely to be achieved in small samples. The analyses and bootstrap estimates that follow are based on 5,000 bootstrap samples (Preacher \& Hayes, 2008).

We conducted two mediation analyses. One comparing both pride conditions (low vs. high pride) and one comparing both empathy conditions (low vs. high empathy). In both analyses, eagerness and willingness are the mediating variables, and knowledge sharing intention is the dependent variable.

The first mediation analysis compared the mediating effect of the low pride vs. high pride condition on knowledge sharing intention via eagerness and willingness. Again confirming $\mathrm{H} 1$, both eagerness, $b=0.81, S E=0.11, \beta=.55, p<.001$, and willingness, $b=0.41, S E=0.10, \beta=$ $.35, p<.001$, were higher in the high pride condition than the low pride condition. Willingness, 
in turn, was positively related to knowledge sharing intention, $b=0.63, S E=0.11, \beta=.45, p<$ .001. Eagerness, however, was not significantly related to knowledge sharing intentions, $b=$ $0.18, S E=0.10, \beta=.16, p=.081$. The specific mediation analysis showed that the total effect of low versus high pride on knowledge sharing intention before the mediators were included was significant, $b=0.69, S E=0.13, \beta=.42, p<.001$. Thus, knowledge sharing intention was higher in the high pride condition than the low pride condition. The direct effect of low versus high pride after the mediators were included was also significant albeit less pronounced, $b=0.28, S E$ $=0.14, \beta=.17, p=.041$, suggesting partial mediation.

Both eagerness and willingness significantly mediate the relationship between low versus high pride and knowledge sharing intention. The indirect effect via eagerness had a point estimate of $0.14, S E=0.08,95 \%$ bias corrected and accelerated confidence interval (95\% Bca CI) [.002, .300]. The indirect effect via willingness had a point estimate of $0.26, S E=0.08,95 \% \mathrm{Bca} C \mathrm{CI}$ $[.127, .444] .{ }^{2}$ In all, the total model for knowledge sharing intention was significant, adj. $R^{2}=$ $.39, F(3,123)=28.40, p<.001$. Contrast analysis comparing the size of the indirect effects of eagerness and willingness did not reveal a significant difference between the size of the indirect effects, $95 \%$ Bca CI [-.358, .080].

The second mediation analysis compared the mediating effect of the low empathy vs. high empathy condition on knowledge sharing intention via eagerness and willingness. Confirming $\mathrm{H} 2$, both eagerness, $b=0.77, S E=0.11, \beta=.53, p<.001$, and willingness, $b=0.66, S E=0.12$, $\beta=.46, p<.001$, were higher in the high empathy condition than the low empathy condition. Both eagerness, $b=0.24, S E=0.12, \beta=.18, p=.048$, and willingness, $b=0.52, S E=0.12, \beta=$ $.39, p<.001$, in turn, were positively related to knowledge sharing intention. The total effect of low versus high empathy on knowledge sharing intention before the mediators were included was significant, $b=1.04, S E=.14, \beta=.55, p<.001$, indicating that knowledge sharing intention was higher in the high empathy condition than the low empathy condition. The direct effect of low versus high pride after the mediators were included was also significant, $b=0.51, S E=0.14$, $\beta=.27, p<.001$, suggesting partial mediation. Both eagerness and willingness significantly mediate the relationship between low versus high empathy and knowledge sharing intention. The indirect effect via eagerness failed to reach significance, with a point estimate of $.18, S E=.10$, $95 \%$ Bca CI [-.001, .384]. The indirect effect via willingness was significant, with a point estimate of $.34, S E=.11,95 \%$ Bca CI $[.175, .590]$. In all, the total model for knowledge sharing intention was significant, adj. $R^{2}=.50, F(3,121)=42.04, p<.001$. Again, contrast analysis comparing the size of the indirect effects of eagerness and willingness did not reveal a significant difference between the size of the indirect effects, 95\% Bca CI [-.532, .132].

In sum, H3a was mostly confirmed. The mediation analysis showed that both eagerness and willingness significantly mediated the relationship between pride and knowledge sharing intention. However, only willingness mediated the relationship between empathy and knowledge sharing intention. H3b was not confirmed; contrast analysis did not show a significant difference in the size of the indirect effects of eagerness and willingness for the relationship between pride

\footnotetext{
${ }^{2}$ An indirect effect is significant when the confidence interval does not contain zero.
} 
and knowledge sharing intention. H3c was partly confirmed. Only the indirect effect of empathy on knowledge sharing via willingness was significant. Eagerness was not a significant mediator. However, the contrast analysis showed that the size of the indirect effects did not significantly differ. Therefore, we cannot conclude that willingness more strongly mediates the relationship between empathy and knowledge sharing intention than eagerness.

\section{DISCUSSION}

In answer to our research question, our findings show that pride and empathy do affect eagerness and willingness to share knowledge. Furthermore, these emotions also influence knowledge sharing intentions, partly mediated by eagerness and willingness: both eagerness and willingness mediate the relationship between pride and knowledge sharing intention. However, only willingness turned out to mediate the relationship between empathy and knowledge sharing. These findings have a number of implications for theory on both knowledge sharing and emotions.

One of the central assumptions behind this study was that emotions are an important factor in explaining knowledge sharing. Our findings indicate that this is indeed the case: the emotional state that an individual is in at a certain moment, is likely to influence his or her attitude towards knowledge sharing as well as his or her intention to actually share knowledge. Therefore, our findings contribute to the literature on knowledge sharing by highlighting the role of emotions, providing empirical insight into the role that emotions play in people's intentions (and subsequent behavior) in terms of knowledge sharing. With that, we add to the practice-based literature on knowledge (e.g, Brown \& Duguid, 2001; Cook \& Brown, 1999; Hislop, 2002) by providing additional insight into the "emergent" or bottom-up character of knowledge sharing, and the factors influencing that process.

In that process, people's intrinsic motivations are especially important (Osterloh \& Frey, 2000), and those intrinsic motivations are influenced by their attitudes towards both the collective, and the practice that this collective (and they as individuals) engage in. The distinction between eagerness and willingness to share appears to be a valuable one, as we find that these attitudes both play a role in explaining knowledge sharing intentions, and that they are both influenced differently by the emotions of pride and empathy. Using attitudes as mediators between emotions and (intentions towards) behavior thus contributes to the literature on emotions, as it provides new insights into how emotions influence behaviors. Our findings show that emotions do have a direct influence on knowledge sharing intentions, but that there is also an interesting mediating role for different attitudes.

Pride was found to affect both eagerness and willingness, and both eagerness and willingness mediate therelationship between pride and knowledge sharing intention. This seems to confirm the statement that pride may be primarily be an ego-focused emotion, but that it does have a collective element as well: public appraisal of expertise, skill and performance contributes to evoking pride (Williams \& DeStento, 2008), and in that sense pride is not an exclusively individual emotion. Consequently, it does make one eager to share out of the wish to showcase 
one's expertise, but not without an eye for the collective interest: pride invokes both eagerness and willingness, so collective performance is a relevant motivation for people feeling pride as well. At least for those feeling what is called achievement-oriented or authentic pride, which stems from mastering a skill, receiving a high academic mark and being recognized for that (Tangney, 1999; Tracy \& Robins, 2004), as opposed to what is called hubristic pride, which has no particular target and refers to an unconditionally positive view of oneself. Authentic pride is in essence adaptive to the social context, whereas hubristic pride is entirely self-focused (Lewis, 1997; Williams \& DeStento, 2008). Actually, hubristic pride may be more of a personality trait than an actual emotion, due to its stable and lasting nature. It might well be that hubristic pride would only invoke eagerness to share, since it lacks the feeling for social context that is a part of achievement-oriented pride.

Consistent with our expectations, empathy seems to transmit its effect on knowledge sharing primarily by affecting willingness to share knowledge, not by increasing eagerness. Willingness was the only significant mediator of the relationship between empathy and intention to share, the mediating effect for eagerness was not found to be significant. In spite of the fact that the contrast analysis showed no significant difference in the size of the indirect effects for eagerness and willingness, this is a clear indication that willingness does play a role in the relationship between empathy and intention to share, and eagerness does not. This means that our theoretical argumentation that empathy can also enhance the feeling that what one knows is very valuable to others, enhancing one's own passion for the practice and thus positively influencing the eagerness to share, does not hold. Where (authentic) pride clearly has an other-focused element in it, next to its ego-focus, the reverse does not hold for empathy: empathy is a fully otherfocused emotion, and motivates the individual to primarily focus on the collective interests. This is in line with research that consistently finds a positive relationship between empathy and prosocial behavior (Eisenberg \& Fabes, 1990).

In conclusion, our findings have implications for theory on both emotions and knowledge sharing. As the two concepts have not been related in a systematic way before, clarifying the relationships between ego- and other-focused emotions on the one hand, and attitudes and intentions towards knowledge sharing on the other, is a contribution to both literatures. Our findings emphasize the need to include emotions more explicitly into research concerning knowledge sharing. By connecting these two areas of research, this study provides new interdisciplinary insights. The findings of this study can be the basis for future research in which more emotions can be included, providing a more detailed picture of which emotions exert influence on knowledge sharing, and the mechanisms through which this influence takes shape. It would be interesting, for instance, to compare the influence of positive emotions (such as enthusiasm, empathy and happiness) on knowledge sharing with negative emotions such as anger, fear and grief. In our study, only two emotions were studied, both of them positive. In that sense, our study serves as a first exploration of the interesting interplay between emotions and knowledge sharing. 


\section{REFERENCES}

Aaker, D. A., Stayman, D.M. \& Hagerty, M.R. (1986). Warmth in advertising: Measurement, impact, and sequence effects. Journal of Consumer Research,12, 365-381.

Aaker, J.L. \& Williams, P. (1998). Empathy versus pride: The influence of emotional appeals across cultures. Journal of Consumer Research 25(3), 241-261.

Adler, P. S., \& Kwon, S.-W. (2002). Social capital: Prospects for a new concept. Academy of Management Review 27(1), 17-40.

Bagozzi, R.P. (1981). Attitudes, intentions and behavior: A test of some key hypotheses. Journal of Personality and Social Psychology 24, 426-435.

Bagozzi, R.P., Gopinath, M. \& Nyer, P.U. (1999). The role of emotions in marketing. Journal of the Academy of Marketing Science 27(2), 184-206.

Baron, R.M. \& Kenny, D.A. (1986). The moderator-mediator variable distinction in social psychological research: Conceptual, strategic, and statistical considerations. Journal of Personality and Social Psychology 51(6), 1173-1182.

Brown, J.S., \& Duguid, P. (2001). Knowledge and organization: A social-practice perspective. Organization Science 12, 198-213.

Cook, S. \& Brown, J.S. (1999). Bridging epistemologies: The generative dance between organizational knowledge and organizational knowing, Organization Science 32, 554-569.

Davis, F.D., Bagozzi, R.P. \& Warshaw, P.R. (1989) User acceptance of computer technology: a comparison of two theoretical models. Management Science, 35(8), 982-1002.

Davis, M.H. (1983). Measuring individual differences in empathy: Evidence from a multidimensional approach. Journal of Personality and Social Psychology 44(1), 113-126.

De Vries, R.E., Van den Hooff, B. \& De Ridder, J.A. (2006). Explaining knowledge sharing: the role of team communication styles, job satisfaction and performance beliefs. Communication Research 33(2), 115-135

Eisenberg, N. \& Fabes, R.A. (1990). Empathy: Conceptualization, measurement and relation to pro-social behavior. Motivation and Emotion, 14(2), 131-149.

Fazio, R.H., Chen, J.M., McDonel, E.C. \& Sherman, S.J. (1981). Attitude accessibility, attitudebehavior consistency and the strength of the object-evaluation association. Journal of Experimental Psychology 18, 339-357.

Fishbein, M. \& Ajzen, I. (1975). Belief, Attitude, Intention and Behavior: An Introduction to Theory and Research. Reading, MA: Addison-Wesley.

Hislop, D. (2002). Mission impossible? Communicating and sharing knowledge via information technology, Journal of Information Technology 17, 165-177.

Kleinginna, P. \& Kleinginna, A.M. (1981). A categorized list of emotion definitions, with suggestions for a consensual definition. Motivation and Emotion 5(4), 345-379.

Markus, H. \& Kitayama, S. (1991). Culture and the self: Implications for cognition, emotion and motivation. Psychological Review 98, 224-253.

Mueller, B. (1987). Reflections of culture: An analysis of Japanese and American advertising appeals. Journal of Advertising Research 27, 51-59.

Kane, A.A., Argote, L. \& Levine, J.M. (2005). Knowledge transfer between groups via personnel rotation: Effects of social identity and knowledge quality. Organizational Behavior and Human Decision Process 96, 56-71. 
Kim, M.S. \& Hunter, J. S. (1993). Relationships among attitudes, behavioral intentions, and behavior: A meta-analysis of past research part 2. Communication Research 20(3), 331364.

Lewis, M. (1997). The self in self-conscious emotions. In J. G. Snodgrass \& R. L. Thompson (Eds.), Self across psychology: Self-recognition, self-awareness, and the self-concept (pp. 119-142). New York: New York Academy of Sciences.

Matsumoto, D. (1989). Cultural influences on the perception of emotion. Journal of Cross Cultural Psychology, 20, 92-105.

Nahapiet, J. \& Ghoshal, S. (1998) Social capital, intellectual capital, and the organizational advantage. Academy of Management Review 22, 242-266.

Osterloh, M. \& Frey, B.S. (2000). Motivation, knowledge transfer and organizational forms. Organization Science 11(5), 538-550.

Preacher, K.J. \& Hayes, A.F. (2008). Asymptotic and resampling strategies for assessing and comparing indirect effects in multiple mediator models. Behavior Research Methods 40 (3), 879-891

Roberts, W. \& Strayer, J. (1996). Empathy, emotional expressiveness, and prosocial behavior. Child Development, 67, 449-470.

Tangney, J. P. (1999). The self-conscious emotions: Shame, guilt, embarrassment and pride. In T. Dalgleish \& M. J. Power (Eds.), Handbook of cognition and emotion (pp. 541-568). New York: Wiley.

Tracy, J. L., \& Robins, R. W. (2004). Putting the self into self-conscious emotions: A theoretical model. Psychological Inquiry, 15, 103-125.

Van den Hooff, B. \& Huysman, M. (2009). Managing knowledge sharing: Emergent and engineering approaches. Information \& Management 46(1), 1-8.

Warshaw, P.R. (1980). A new model for predicting behavioral intentions: An alternative to Fishbein. Journal of Marketing Research 17, 153-172.

Wasko, M.M. \& Faraj, S. (2005). Why should I share? Examining social capital and knowledge contribution in electronic networks of practice. MIS Quarterly 29(1), 35-57

Williams, L.A. \& DeSteno, D. (2008). Pride and perseverance: The motivational role of pride. Journal of Personality and Social Psychology 94(6), 1007-1017.

Wenger, E., McDermott, R. \& Snyder, W. (2002). Cultivating Communities of Practice. Boston, MA: Harvard Business School Press.

Zammuner, V. C. (1996). Felt emotions, and verbally communicated emotions: The case of pride. European Journal of Social Psychology 26, 233-245. 